\title{
Disparity between reimbursement-driven practice and humanistic values of occupational therapy.
}

Janice P. Burke

Thomas Jefferson University

Joanne C. Cassidy

Thomas Jefferson University

Follow this and additional works at: https://jdc.jefferson.edu/otfp

Part of the Occupational Therapy Commons

Let us know how access to this document benefits you

\section{Recommended Citation}

Burke, Janice P. and Cassidy, Joanne C., "Disparity between reimbursement-driven practice and humanistic values of occupational therapy." (1991). Department of Occupational Therapy Faculty Papers. Paper 35.

https://jdc.jefferson.edu/otfp/35

This Article is brought to you for free and open access by the Jefferson Digital Commons. The Jefferson Digital Commons is a service of Thomas Jefferson University's Center for Teaching and Learning (CTL). The Commons is a showcase for Jefferson books and journals, peer-reviewed scholarly publications, unique historical collections from the University archives, and teaching tools. The Jefferson Digital Commons allows researchers and interested readers anywhere in the world to learn about and keep up to date with Jefferson scholarship. This article has been accepted for inclusion in Department of Occupational Therapy Faculty Papers by an authorized administrator of the Jefferson Digital Commons. For more information, please contact: JeffersonDigitalCommons@jefferson.edu. 


\section{Disparity Between Reimbursement-Driven Practice and Humanistic Values of Occupational Therapy}

I n January 1990, clinicians, educa tors, and researchers met at the Directions for the Future Sympo. sium in San Diego to delineate, discuss, and debate a wide range of eco nomic, political, and social issues that are influencing the evolution of occupational therapy practice and education. By examining these factors in an open and thorough way, therapists believe they will be able to develop proactive positions that will ensure the continued well-being of the field.

In this paper, we will consider two distinctly opposing forces that dramatically affect and present considerable obstacles to occupational therapists. On the one hand, occupa. tional therapists are taught to embrace a fundamental, humanistically based philosophy of practice that em phasizes the importance of the indi. vidual. On the other hand, they are expected to practice in an economically defined health care environment, where issues of reimbursement for service are highly valued and are among the key factors to be consid. ered when making evaluation and treatment decisions.

\section{Humanistic-Valued Practice}

Adolf Meyer is among the early leaders of the field credited with advocating treatment that centers on a "profound respect for the patient and his efforts to get through this life with a maximum of gratification and a min. imum of discomfort" (Muncie, 1959, p. 1322). During the early years of the profession's development, this notion formed the keystone of professional practice. This approach directed therapists to emphasize work, play, and social activities and placed with therapists a moral obligation and responsi. bility as agents of society to any per-

\section{Janice Posatery Burke, Joanne C. Cassidy}

Janice Posatery Burke, MA, OTR/L, FAorA, is Assistant Professor, Department of Occupational Therapy, Thomas Jefferson University, 130 South Ninth Street, Philadelphia, Pennsylvania 19107.

Joanne C. Cassidy, MEd, OTR/L, is Chief Occupational Therapist, Department of Rebabilitation Medicine, Thomas Jefferson University Hospital, Pbiladelphia, Pennsylvania.

This article was accepted for publication October 15, 1990

son whose future as a member of that society was jeopardized (Bockoven, 1971). With this perspective, occupational therapists placed the utmost re spect on "human individuality and on a fundamental perception of the indi. vidual's need to engage in creative activity in relation to his fellow man'" (Bockoven, 1971, p. 223). This initial orientation is still very much a part of current practice, as evidenced by the preamble to the Occupational 7her. apy Code of Etbics (American Occupational Therapy Association [AOTA], 1988), which states that therapists "are committed to furthering people's ability to function fully within their total environment" (p. 795).

Additional concepts and con cerns such as habit training were added to our repertoire of characteris. tically humanistic-based practice and directed us toward an involved role with our patients. As a primary aspect of treatment, habit training was used to enlist patients' interests as they established a sense of personal useful- ness. To do so, therapists were taught to consider the person as well as the environment and the effect each had on the other (Ryon, 1925; Slagle, 1934).

Throughout its professional de. velopment, occupational therapy has continued to remain strongly oriented to the individual. Information was accumulated that would allow therapists to administer evaluation and treatment that would be highly sensitive to and inclusive of an individual's cul. ture, values, and beliefs. Therapists found that involvement of the patient in his or her own treatment was the most natural way to ensure behavioral change. The patient's goals were used to form the basis of the treatment ses. sion, and the patient's active involve ment was enlisted to ensure a suc. cessful outcome. It followed that if therapists were to create individually designed, personally meaningful treatment programs, then they must spend considerable time and energy getting to know each patient as a person. In this way, the therapist could determine what was needed.

Our conflict in the 1990s lies in how these individually oriented, humanistic values can survive within the current climate of health care. What economic, political, and social factors are impinging on our deeply ingrained humanistic philosophy of care, and how shall we act in relation. to those forces?

\section{Shifting Our Allegiance}

In the current practice of occupational therapy, we have been forced to shift our allegiance from focusing solely on the patient to a more expanded concern that incorporates the needs of our employers to remain fi- 
nancially solvent. This shift has increased our attention to efficient dis charges, shortened lengths of stay, maintenance of high census, develop. ment of referral networks, and provi sion of care in the least costly way. Like physicians, we have had to amend our traditional allegiance to the patient due to increased fiscal restraint, which requires that we now consider the economic realities of the hospitals in which we work. We must interweave the moral commitment we have to the individual with the economic responsibilities we have to our employer (Cassidy, 1988). This dilemma surfaces daily in outpatient care, where patterns for reimburse. ment for services are typically narrowly defined and limited in scope. This has resulted in an environment in which conflicting forces are at work: People have a need for the service, and therapists are trained to provide the needed service, but there is no viable mechanism available to pay for the service. Many times, because of a patient's lack of health insurance, we must turn even the most appropriate treatment candidates away from our departments. In present day practice, "the economics of the system rather than the need or condition of the patient dictates the amount and level of occupational therapy service" (Perinchief, 1988, p. 166).

Another effect of this economically driven situation is that we are faced with the pressure of providing a certain treatment protocol that is based on diagnosis. The frequency of treatment is dictated not by the patients' needs but rather by administrative directive. To follow this directive guarantees a charge for the cost of rehabilitation while that patient is eligible for such charges based on thirdparty reimbursement criteria (Neuhaus, 1988).

In reimbursement-driven practice, many decisions are predicated on factors outside of the therapist. Indeed, changing reimbursement patterns have demanded new service provision models. We must therefore ask ourselves whether we as occupa. tional therapists will be able to create new treatment models that meet reimbursement guidelines and still maintain our strong commitment to individuals, holistic care, and occupational role performance.

More and more it appears that we must use a technical, protocoldriven approach to treatment. This mechanistic approach clashes with our preferred approach to the person as an indiviclual, because, according to Neuhaus (1988), we must practice "in a climate where technology and cost containment may overshadow the needs of the individual patient" ( $p$. 288). The conflict is further complicated, because "it is difficult to set re alistic priorities that have some meaning for the patient when the patient's length of hospital stay has been determined on the basis of a diagnostic category that denies the individuality of the patient in general as well as the specific needs of that particular person" (Neuhaus, 1988, p. 291).

These obvious practice dilemmas raise key questions, such as (a) Does providing cost-effective care mean giving up quality of care and a commitment to quality-of-life issues? (b) Do we have enough time to get to know the person, develop individually valued goals, elicit motivation and participation, and provide opportunities for individually meaningful successes? and (c) Are we uncomfortable with providing what we may consider to be less than quality care and compensating in other ways, such as prescribing additional or special adaptive devices and equipment?

\section{Identifying the Consumer}

The term consumer is no longer re served for the patient alone; it now extends to the government (policymakers, legislators, health care systems), health maintenance organizations, third-party payers, for-profit hospital corporations, and school administrators. With this expanded roster of agents to whom the therapist is held accountable comes the pressure of a complex of concerns and vested interests that increase the likelihood of ethical conflicts (Hansen, 1990).

Demonstrating our effectiveness to third-party reimbursers requires that we be able to explain and justify treatment to a variety of administrators and health and education offi. cials. Again, the nature of our practice conflicts with how outsiders view efficacy. Occupational therapy goals are oriented to the inclividual, and the outcomes of treatment are individu. ally significant; by their nature, these outcomes are not statistically signifi. cant. Conversely, in economics, belief systems are built when proof is generated in large numbers that can be generalized to the population.

Where reimbursement issues are concerned, other persons, including families who may be paying a signifi. cant portion of the bill, will also need to understand and have trust in the rationale behind our treatment methods if they are going to invest their money in such treatment. In addition to paying for our services, families will have to invest their interest and time by actively participating in treatment with their family member. This unusual demand on our part contrasts with the more traditional and authoritarian position taken by other health care practitioners. Rather than being asked to stand aside and relinquish control, families are required to actively participate in the problem solv. ing, decision making, and implementation of treatment. Surprised by this demand for involvement, families may grapple with the perceived value of such therapy. Their confusion is typified by their repeated inquiries for an explanation of our service, especially in terms of the outcomes they can expect for their family member. Many therapists find these inquiries difficult to handle. Their reluctance to promise outcomes stems from their respect for the individual and their knowledge of the complex factors that influence behavior and skill development.

The need to influence public pol. icymakers, legislators, and insurance regulatory bodies to ensure our inclusion in standards and regulations for health care and associated policy decisions (e.g., education, home care, employment) requires us to move in many other unfamiliar ways. Will we be able to convince them that occupational therapy is a primary and essential service (Cassidy, 1988)? Our ability to do this may be influenced by how different and almost simplistic our practice looks, with its focus on daily living skills, as compared with 
the high-tech professions and environments in which we practice (Burke, 1984).

The subtle complexity of everyday activities (Fleming, 1990) may appear to be less important or to require less professional skill when compared with the operating suite, a physical therapy hydrotherapy unit, or a dialy. sis unit. Our practice, which uses commonsense objects in everyday ways, may cause orhers to diminish our importance and our skill as part of a modern health care team (Fleming, 1990).

Our role in home care exemplifies this dilemma. In home care reimbursement regulations, occupational therapy is considered a secondary service. This means that an occupational therapist is unable to open a case and provide intervention to the increasing number of homebound patients who are leaving acute care settings before they have been able to fully benefit from occupational therapy. Because therapists are working under the restricted timetables of acute care, they will frequently sketch out a brief plan to justify further occupational therapy for a given patient who is homebound. When the patient is discharged and assigned to a home health agency, the occupational therapy plan is reviewed by a primary ser vice provider, typically a nurse or a physical therapist. Upon reading the plan to provide training for daily liv ing skills, a nurse or physical therapist will often ignore the unstated expertise that is required to teach daily living skills and instead assume by the very commonness of the goals and activities that his or her own treatment plan will suffice toward the accomplishment of these goals.

\section{Summary}

The humanistic-driven versus reimbursement-driven issues that we have outlined present complex ethical dilemmas to occupational therapists concerned with "assuring the best quality of life possible for their patients" (Hansen, 1990, p. 4). As we approach the 21st century, we find ourselves increasingly involved in a careful examination of the "ethical parameters of our practice" (Hansen,
1990, p. 7). As called for by AOTA's Directions for the Future plan (Flem. ing, Johnson, Marina, Spergel, \& Townsend, 1987), we must make some decisions and act in ways that will lead to our appropriate inclusion in the health care marketplace. Some of those ways are outlined in the directives below.

Establish mechanisms to ensure that patients receive occupational therapy. Ideally, the acute care role for which we are best suited is triage. In triage, we would assess the person's level of need and his or her readiness to engage in rehabilitation. On the basis of assessment findings, a patient would be assigned to a rehabilitation setting, nursing home, out patient care setting, or home health care agency. This would depend on our ability to secure our role as essen. tial service providers

Resolve personnel issues, especially in the areas of retention and recruitment. Therapists may not be attracted to or be able to stick with positions in acute and rehabilitation care centers because of their frustration with the medical model; the associated lack of support for the kind of service we want to give; and the burnout we experience from the high-paced, mechanically and technically centered care. Implementation of strategies such as the triage system outlined above may help us to miti. gate our personnel shortages.

Increase the social commitment to the value of bealth. Current societal values associated with health care provision are reflected in an unequal provision of service based on eco nomic and social class, including racial and ethnic distinctions. Why are some people turned away from health and rehabilitation programs while others are allowed to receive care for varying periods of time and in a vari. ety of settings? Once we affirm that all people have an equal right to equal health care, we will be able to provide occupational therapy in a way that is consistent with our humanistic philosophy.

Develop an acute awareness of and knowledge about bealth care re. imbursement. Information on "the limitation of that coverage and of the alternatives for coverage" (Perinchief,
1988 , p. 166) is critical in planning and implementing optimum trearment programs. Such information can help therapists succeed in their "unspoken contract with the patient to provide optimum care, which in cludes ensuring that the service provided is reimbursable" (Moyers, 1990 , p. 15). Additionally, a thorough investigation of alternative and less costly service provision models, such as consultation, and the effect of these models on patient care status must be acted on.

Educate consumers. As consumers assume the responsibilities of their role, they will harness their power and position with reimburse. ment sources. Educated consumers will be able to turn their anger and frustration at being denied rehabilitation or occupational therapy for home health care into efforts to call, write, lobby, and otherwise influence their lawmakers and their insurance agencies. By doing so, consumers ensure that the health policies and proce dures reflecting their true preferences for care are appropriately developed and included in laws and regulations governing health care.

\section{References}

American Occupational Therapy As. sociation. (1988). Occupational therapy code of ethics. American Journal of Occupational Therapy, 12, 795-796.

Bockoven, J. S. (1971). Occupational therapy-A historical perspective Legacy of Moral Treatment-1800's to 1910. American Journal of Occupational Therapy, 25, 223-225

Burke, J. P. (1984). Occupational therapy: A focus for roles in practice. American Journal of Occupational Therapy, 38, 24-28.

Cassidy, J. C. (1988). Access to health care: A clinician's opinion about an ethical issue. American Journal of Occu. pational Therapy, 42, 295-299.

Fleming, M. (1990). A common sense practice in an uncommon world. Paper presented at the Institute on Clinical Reasoning, Tufts University-Boston School of Occupational Therapy, Medford, MA Fleming, M. H., Johnson, J. A., Ma rina, M., Spergel, E. L., \& Townsend, B. (Eds.). (1987). Occupational therapy: Directions for the future. Rockville, MD: American Occupational Therapy Association.

Hansen, R. (1990). Ethical considerations. In C. B. Royeen (Ed.), AOTA self study series: Assessing function (No. 10). 
Rockville, MD: American Occupational Therapy Association.

Movers, P. (1990). Reimbursement for functional assessment. in C. B. Royeen (Ed.), AOTA self study series: Assessing function (No. 8). Rockville, MD: American Occupational Therapy Association.

Muncie, W. (1959). The psychobiolo. gical approach. 1n S. Arieti (Ed.), American bandbook of psychiatry (vol. 11, pp. 1317-1335). New York: Basic

Neuhaus, B. E. (1988). Ethical considerations in clinical reasoning: The impact of technology and cost containment.
American Journal of Occupational Ther. apy, 42, 288-294.

Perinchief, J. (1988). Influences of the health care system on occupational therapy practice. In $\mathrm{H}$. Hopkins \& $\mathrm{H}$. Smich (Eds.), Willard and Spackman's oc cupational therapy (7thed.) (pp. 165-167). Philadelphia: Lippincou. Rvon, W. G. (1925). Habic raining for mental patients. Occupational Tberapy and Rehabilitatiom, 4, 235-239.

Slagle, E. (1934). Occupational ther. apv: Recent methods and advances in the United States. Occupational Therapj' and Rebabilitation, 13, 289-298.
THE ISSUE IS provides a fortum for debale and discussion of occupational therapy is sues and related topics. The Contributing Editor of this section, Iulia Van Deusen, striles to bave both sides of an isste ad. dressed. Readers are encouraged to sub. mit manuscripts discussing opposite points of lieu or neu topics. All manuscripts are subject to peer retitu. Submit three copies to Elaine Viseltear, Editor.

Published articles reflect the opinion of the awthors and are selected on the basis of interest to the profession and quatity of the discussion.

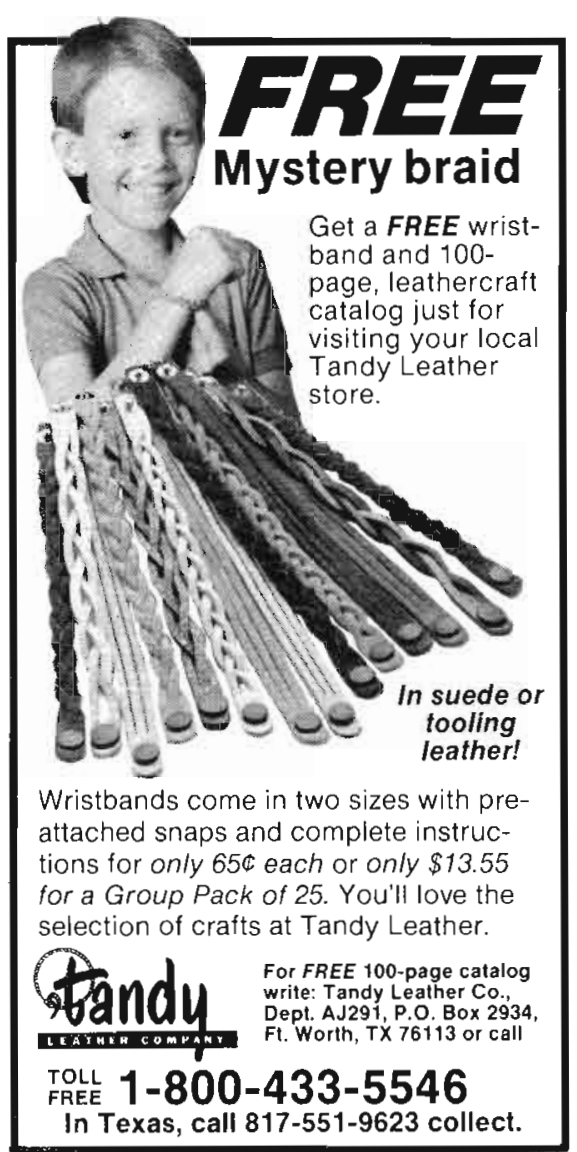

176

\section{RECALL OF SOUTHPAW ENTERPRISES, INC., THERAPY ROPE (BS-150) WITH EYE SPLICE (BS-151)}

Dear Customer:

Southpaw Enterprises, Inc., is recalling all Therapy Ropes with Eye Splices purchased between April, 1990 and January 4, 1991. Immediately discontinue use of all Therapy Ropes with Eye Splices purchased during this time frame. Eye Splice could fail without warning.

The Therapy Rope must be cut into lengths less than 3 feet and disposed of (white/blue ropes). Enclosed with the new Therapy Rope is a red tag warning label to be attached to the defective eye splice.

We are sending new Therapy Rope (BS-150) with Eye Splice (BS-151), the same dimension as previously ordered, under separate cover to the Ship To address on the Sales Order. (Please note, new ropes are orange/blue.)

New Therapy Rope with Eye Splice has been tested and exceeds Highest Safety Standards.

If you have any questions, call Southpaw Enterprises, Inc., at 1-800-228-1698. 